\title{
PERBANDINGAN KAPASITAS LATERAL TIANG PANCANG TUNGGAL (SHORT PILE) KONDISI FIXED END ANTARA UJUNG BAWAH TERBUKA DENGAN TERTUTUP PADA TANAH PASIR (NON-KOHESIF)
}

\author{
Indra Setya Putra \\ Balai Rawa, Pusat Penelitian dan Pengembangan Sumber Daya Air - Kemen. PU \\ Telp.0511-3256623, Email: qmbut@yahoo.com
}

\begin{abstract}
Abstrak
Pondasi tiang pancang tunggal pada bangunan biasanya dirancang untuk menahan beban aksial dan beban horizontal/lateral pada tanah lapisan keras yang biasanya terletak di dekat permukaan. Penelitian tentang kapasitas lateral pondasi dalam permodelan masih sangat jarang dilakukan oleh para ahli. Tujuan penelitian ini adalah membandingkan tahanan lateral $(\mathrm{Qu})$ pondasi tiang pancang tunggal kondisi kepala tiang jepit (fixed end) ujung bawah terbuka dengan ujung bawah tertutup. Pengujian dilakukan dengan model skala kecil dengan pasir sebagai medium dan mempunyai eksentrisitas $20 \mathrm{~cm}$ dari muka tanah serta kedalaman tiang $20 \mathrm{~cm}$. Tiang diameter bervariasi $1 \mathrm{~cm}, 1,25 \mathrm{~cm}, 1,5 \mathrm{~cm}$. Nilai Qu dari interpretasi data dihitung dengan menggunakan metode Mazurkiewicz's sedangkan analisis dengan metode Broms, 1964. Penelitian ini menghasilkan kesimpulan bahwa tahanan lateral (Qu) ujung terbuka cenderung lebih besar daripada ujung tertutup. Interpretasi data tiang ujung terbuka cenderung lebih mendekati hasil analisa metode Brom dibandingkan tiang ujung tertutup.
\end{abstract}

Kata kunci : tiang ujung tertutup, tiang tunggal ujung terbuka, tahanan lateral, tanah pasir

\begin{abstract}
Single short pile foundation in building usually designed to retain both axial load and horizontal load in hard soil layer which is usually lied near the surface. Researchs about foundation's lateral capacity in the modelling are rarely conducted by experts. The objectives of this research are to compare between lateral capacity $(\mathrm{Qu})$ of single short pile with fixed end cap condition of openedlower end and that of closed-lower end with small scale model in the laboratorium and to compare the results of the test with that of analysis. The test conducted with small scale model with sand as the medium and eccentricity is about $20 \mathrm{~cm}$ from soil surface also the depth is about $20 \mathrm{~cm}$ from soil surface. Pile's diameters vary in $1 \mathrm{~cm}, 1,25 \mathrm{~cm}$ and 1,5 cm. Qu calculated from datum with Mazurkiewicz's method, otherwise the analysis uses Broms, 1964 method. The research concludes that lateral capacity of opened-lower end tends to higher than that of closed-lower end. Datum interpretation of opened-lower end tends to closer with Brom's analysis than that of closed-ower end.
\end{abstract}

Keywords : closed-lower end, opened-lower end, lateral capacity, sands

\section{PENDAHULUAN}

Pondasi tiang adalah bagian konstruksi yang dibuat dari kayu, beton dan/atau baja, yang digunakan untuk meneruskan (mentransmisikan) beban permukaan ke tingkat permukaan yang lebih rendah dalam massa tanah. Beban terdistribusi sebagai beban vertikal dari beban sepanjang poros tiang pancang atau pemakaian beban secara langsung terhadap lapisan yang lebih rendah melalui ujung tiang pancang. ${ }^{(1)}$ Pondasi tiang selain dirancang untuk menahan beban-beban aksial, juga sering harus dirancang dengan memperhitungkan beban horizontal/lateral. Sumber-sumber dari beban lateral sendiri antara lain berupa tekanan tanah pada 
dinding penahan, beban angin, beban gempa, beban-beban tubrukan dari kapal (berlabuh, pada dermaga), beban-beban eksentrik pada kolom, gaya gelombang lautan, gaya kabel pada menara transmisi. Di lapangan pondasi tiang bisa terpasang pada kondisi bebas (free-end pile) atau dalam keadaan kepala tiang terjepit (fixedend pile).

Berdasarkan perpindahan tanahnya, pondasi tiang pancang dapat dikategorikan pondasi tiang dikelompokkan menjadi tiang perpindahan besar (large displacement pile) yang mempunyai ujung bawah tertutup, tiang perpindahan kecil (small displacement pile) yang mempunyai ujung bawah terbuka dan tiang tanpa perpindahan (non displacement pile) yang dipasang di dalam tanah dengan cara menggali atau mengebor tanah. ${ }^{(2)}$

Penelitian tentang tiang pancang dalam bentuk pemodelan di laboratorium masih sangat jarang dilakukan oleh para ahli. Penelitian ini dilakukan untuk membandingkan kapasitas tahanan lateral $(\mathrm{Qu})$ pondasi tiang pancang tunggal kondisi kepala tiang jepit (fixed end) ujung bawah terbuka dengan ujung bawah tertutup model tiang skala kecil di laboratorium yang kemudian dibandingkan dengan hasil analisis.

Model tiang menggunakan skala kecil dilakukan di laboratorium dan berbahan aluminium dengan penampang tiang berbentuk lingkaran mempunyai diameter yang berbeda-beda yaitu $1,0 \mathrm{~cm}, 1,25 \mathrm{~cm}$, $1,5 \mathrm{~cm}$. Model tiang yang diuji adalah tiang tunggal dengan dimensi yang ditentukan setelah pengujian nilai El agar didapat model tiang pendek (short pile). Eksentrisitas ditentukan $20 \mathrm{~cm}$ diatas muka tanah dengan pembebanan berupa beban lateral statis kelipatan $200 \mathrm{gr}$. Media tanah yang dipakai pada penelitian ini adalah pasir lepas, kering, berdiameter $0,425 \mathrm{~mm}$ hingga $0,180 \mathrm{~mm}$ (lolos saringan no. 40 dan tertahan saringan no. 80 standar ASTM D422-63). Media tanah yang dipakai adalah pasir kering dengan beberapa alasan yaitu, dipilih pasir dengan pertimbangan sifat teknis pasir tidak dipengaruhi sifat dan ikatan kimia serta kohesi seperti tanah lempung, dan dengan kondisi kering, dengan pertimbangan untuk mengurangi pengaruhnya terhadap parameter media tanah.

\section{BAHAN DAN METODE}

Pondasi tiang digunakan untuk mendukung bangunan apabila lapisan tanah kuat terletak sangat dalam. Penggunaan pondasi tiang pancang dalam hal ini untuk mengimbangi pengaruh beban tersebut. Untuk menentukan $\mathrm{z} / \mathrm{d}$ pada tiang pancang dilakukan dengan mengambil sudut gesek dalam ${ }^{(3)}$.

$\phi^{\prime}=3 \phi+10^{\circ}$

Dimana :

$\phi=$ sudut gesek dalam tanah asli di lapangan

Media tanah yang digunakan adalah pasir. Pasir merupakan salah satu jenis tanah yang mempunyai peranan salah satunya sebagai pendukung dari suatu pondasi. Dalam standar ASTM D422-61T, pasir digolongkan ke dalam pasir halus jika diameter butirannya antara 0,074-0,42 mm. Untuk pasir sedang, diameter butirannya antara 0,42-2 $\mathrm{mm}$, dan digolongkan dalam pasir kasar jika diameter butirannya antara 2-4,76 mm.

Kapasitas pondasi pada tanah pasir, dipengaruhi oleh kepadatan relatif (Dr), kedudukan muka air tanah, tekanan sekeliling tanah (confining pressure), dan ukuran dari pondasi. Kepadatan relatif adalah salah satu sifat yang sangat penting artinya bagi pasir, kekuatan geser serta compressibility tergantung pada kepadatan relative. Selain itu daya tahan pasir terhadap gempa bumi atau getaran mesin juga tergantung terutama kepada kepadatan relatifnya. Kepadatan relatif untuk pasir digolongkan dalam kondisi pasir medium jika $\operatorname{Dr}$ antara 0,33 sampai $0,67 \% .^{(4)}$ Nilai kepadatan relatif dapat dicari dengan menggunakan persamaan (2).

$\left.D_{r}=\left(\gamma_{d(\text { maks })} / \gamma_{d}\right)\left\{\left(\gamma_{d}-\gamma_{d(\text { min })}\right) /\left(\gamma_{d(\text { maks })}\right)^{-} \gamma_{d(\text { min })}\right)\right\}$

Dimana :

\begin{tabular}{|c|c|c|c|}
\hline$D_{r}$ & & Kepadatan relatif & \\
\hline$\gamma_{d}$ (maks) & & $\begin{array}{l}\text { Berat volume } \\
\text { maksimum } \\
\text { ditinjau }\end{array}$ & $\begin{array}{r}\text { kering } \\
\text { yang }\end{array}$ \\
\hline$\gamma_{d}$ & & $\begin{array}{l}\text { Berat volume kering } \\
\text { tanah yang ditinjau }\end{array}$ & normal \\
\hline$\gamma_{d}(\min )$ & & $\begin{array}{l}\text { Berat volume kering } n \\
\text { tanah yang ditinjau }\end{array}$ & \\
\hline
\end{tabular}




\section{Kapasitas Lateral pondasi Tiang}

Pondasi tiang selain dirancang dengan memperhitungkan beban-beban aksial, beban lateral juga perlu ikut diperhitungkan. Begitu juga karakteristik tanah yang mendukung pondasi harus ditinjau dalam menentukan kapasitas dukung maksimal lateral dari pondasi tiang. Dua jenis tanah yang ditinjau dalam hal ini adalah tanah kohesif dan tanah non-kohesif. Untuk tanah kohesif, kapasitas dukung ultimit mengandalkan lekatan yang terjadi antara permukaan tiang dengan tanah di sekitarnya, sedangkan untuk tanah nonkohesif kapasitas daya dukung maksimalnya didasarkan pada gesekan antara butir-butir tanah dengan permukaan tiang. ${ }^{(5)}$

\section{Metode Brom (1964)}

Tiang dianggap tiang pendek kaku (short rigid pile) jika $\mathrm{L} / \mathrm{T} \leq 2$ atau $\mathrm{L} / \mathrm{R} \leq 2$ dan dianggap tiang panjang lentur (long flexible pile) jika $L / T \geq 4$ atau $L / R \geq 3,5$, dimana:

$$
\begin{aligned}
& \mathrm{T}=\left(\frac{E I}{n_{h}}\right)^{1 / 5} \\
& \mathrm{R}=\left(\frac{E I}{k_{h}}\right)^{1 / 4}
\end{aligned}
$$

\section{Dimana :}

$$
\begin{array}{lll}
\mathrm{E} & = & \text { modulus elastisitas bahan tiang } \\
& \left(\mathrm{kg} / \mathrm{cm}^{2}\right) \\
\mathrm{I} & = & \text { momen Inersia tiang }\left(\mathrm{cm}^{4}\right) \\
\mathrm{L} & = & \text { panjang tiang pancang }(\mathrm{cm}) \\
k_{h} & = & \text { koefisien reaksi modulus tanah } \\
& \text { horisontal } \\
n_{h} & = & \text { koefisien variasi modulus tanah }
\end{array}
$$

Analisis metode Brom, 1964, untuk tanah kohesif dan tanah non kohesif dilakukan terpisah, demikian juga untuk tiang pendek dan tiang panjang. Analisis tahanan lateral tiang pendek dengan ujung jepit pada tanah non kohesif dengan metode Brom dihitung dengan rumus ${ }^{(6)}$ :

$$
\mathrm{Q}_{\mathrm{u}}=1.5 \mathrm{YL}^{2} \mathrm{BK}
$$

$$
\text { Dimana: }
$$

$$
\begin{aligned}
\mathrm{Y} & =\text { berat isi tanah }\left(\mathrm{kg} / \mathrm{m}^{3}\right) \\
\mathrm{B} & =\text { lebar pondasi }(\mathrm{m}) \\
\mathrm{L} & =\text { kedalaman tiang tertanam }(\mathrm{m}) \\
\mathrm{K}_{\mathrm{p}} & =\text { koefisien tekanan tanah pasif } \\
& \quad \text { Rankine } \\
\mathrm{e} \quad & =\text { jarak beban terhadap permukaan } \\
& \text { tanah }(\mathrm{m})
\end{aligned}
$$

\section{Mekan isme Keruntuhan}

Keruntuhan yang terjadi pada tiang pendek yang berupa rotasi untuk ujung bebas dan translasi untuk ujung jepit menunjukkan bahwa gaya horizontal/lateral yang ada ditentukan oleh sifat-sifat tanah, bukan oleh material tiang yang dilustrasikan pada Gambar 1. Pada tiang panjang baik dalam keadaan ujung bebas atau ujung jepit, keruntuhan yang terjadi berupa patahan, menunjukkan gaya horizontal yang terjadi merupakan gaya horizontal batas Qu yang merupakan fungsi sifat-sifat material tiang. ${ }^{(7)}$

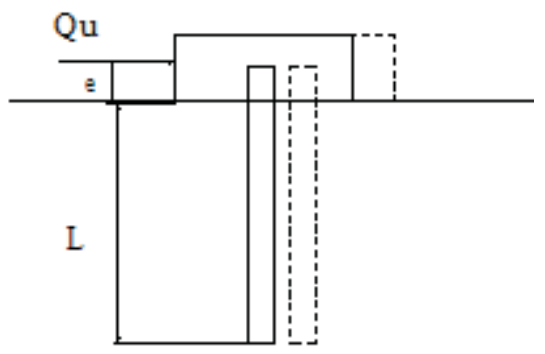

Gambar 1 : Mekanisme keruntuhan pada
tiang pendek tipe fixed end

\section{Pengujian Nilai Modulus Elastisitas Tiang} Nilai modulus elastisitas bahan tiang diperlukan untuk keperluan perhitungan daya dukung tiang dengan metode analisis Brom, Pengujian nilai El, dilakukan dengan alat-alat antara lain tempat perletakan sampel, tempat beban, dan dial gauge. Dial gauge digunakan untuk mengukur defleksi tiang akibat beban geser yang diberikan pada tengah-tengah tiang. Dari nilai defleksi yang terukur untuk pembebanan yang bervariasi, dan nilai panjang serta diameter tiang, maka nilai El dapat diperoleh dari perhitungan secara analisis.

\section{Pengujian Pembebanan}

Pengujian yang dilakukan pada penelitian ini, menggunakan model pondasi tiang dengan jarak kepala tiang dengan muka tanah (e) $20 \mathrm{~cm}$ dan kedalaman dari muka tanah $20 \mathrm{~cm}$. Dari variasi diatas kemudian divariasi lagi dengan 3 diameter yang berbeda yaitu $1 \mathrm{~cm}, 1,25 \mathrm{~cm}$, dan 1,5 $\mathrm{cm}$. Model tiang terbuat dari aluminium dengan 2 macam ujung yaitu ujung bawah terbuka dengan ujung bawah tertutup, dengan ketebalan rata-rata tiang $0,5 \mathrm{~mm}$.

Model tiang yang akan diuji dimasukkan ke dalam bak yang berisi pasir, kemudian diberi beban tarik $200 \mathrm{gr}$ dengan pertimbangan pada beban 200 gram 
perubahan mistar ukur dapat terbaca dengan baik. Pembacaan beban dilakukan setiap menit setelah proses pemberian beban, dan beban ditambah jika dalam waktu lima menit, pergerakan tiang kurang signifikan. Pembebanan dihentikan jika grafik yang dihasilkan sudah mengindikasikan pola-pola keruntuhan. Dan pada penelitian ini tidak dilakukan pengurangan beban. Mekanisme pembebanan dapat dilihat dengan jelas pada Gambar 2.

\section{Metode Interpretasi Data}

Besarnya kapasitas dukung lateral ultimit dari pengujian beban lateral dicari dengan menggunakan interpretasi data. Metode yang dapat digunakan untuk interpretasi data adalah metode Mazurkiewicz's, 1972. Caranya dengan menggambar kurva hubungan beban dan displacement. Kemudian membagi displacement tiang dengan beberapa pias yang sama, dan menggambar garis sampai memotong kurva. Dari perpotongan ini, dibuat garis tegak lurus garis pertama sesuai perpotongan pada kurva dan selanjutnya dibuat garis $45^{\circ}$ dari garis pertama memotong garis berikutnya. kemudian ujung-ujung segitiga yang didapat, digambar garis-garis lurus yang menyinggung setiap ujung segitiga. Perpotongan garis ini dengan sumbu beban merupakan beban ultimit yang dihasilkan.

\section{HASIL DAN PEMBAHASAN}

Pada penelitian ini, pengujian pada parameter tanah dan modulus elastisitas tiang telah dilakukan oleh Kumoro (2004) seperti pada Tabel 1. ${ }^{(8)}$ Dengan data tersebut dapat dihitung kapasitas tahanan lateralya dengan menggunakan metode Brom sesuai dengan diameter tiang masingmasing. Selain itu dari nilai Modulus Elastisitas tersebut dapat diketahui bahwa tiang pancang ini termasuk tipe tiang pendek (short pile).

Grafik interpretasi data dari beban dan displacement yang didapat dari pengujian kemudian dianalisa dengan menggunakan metode Mazurkiewicz's seperti yang diperlihatkan di Gambar 3. Pada gambar tersebut tanda panah yang menghubungkan titik-titik perpotongan menunjukkan angka 3750 yang berarti mempunyai tahan lateral ultimit tiang ujung tertutup diameter $1,5 \mathrm{~cm}$ adalah $3750 \mathrm{gr}$. Dari Tabel 2, persentase selisih yang diperoleh dari metode Mazurkiewicz's, 1972 berbeda-beda. Pada diameter $1 \mathrm{~cm}$ kapasitas tahanan lateral ujung terbuka lebih kecil daripada ujung tertutup, sedangkan pada diameter 1,25 dan 1,5 kapasitas tahanan lateral pada ujung terbuka lebih besar daripada ujung tertutup. Secara keseluruhan tahanan lateral ujung terbuka cenderung lebih besar 12,69\% daripada ujung tertutup. Persentase selisih yang berbeda-beda ini disebabkan oleh pengaruh pemancangan yang menyebabkan tahanan lateral ultimit tiang naik dan pengaruh penutupan ujung bawah tiang yang mengurangi tahanan dari dalam tiang sehingga tahanan lateral ultimitnya berkurang.

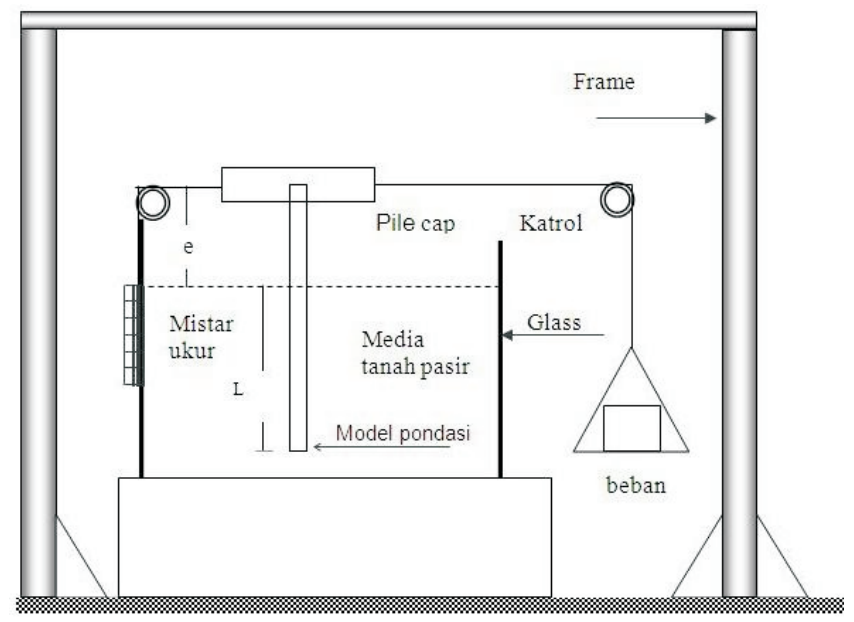

Gambar 2 : Sketsa pengujian model 
Tabel 1. Hasil Uji Parameter Tanah dan EI

\begin{tabular}{|c|l|l|}
\hline No & \multicolumn{1}{|c|}{ Nama Uji } & \multicolumn{1}{c|}{ Hasil } \\
\hline 1 & water content $(w)$ & $0 \%$ \\
\hline 2 & Berat Volume Tanah $(\mathrm{y})$ & $1,5619 \mathrm{gr} / \mathrm{cm}^{3}$ \\
\hline 3 & Sieve Analysis / Analisis Saringan & Sand $100 \%$ \\
\hline 4 & Direct Shear & $\begin{array}{l}\mathrm{c}=0 \mathrm{~kg} / \mathrm{cm}^{2} \\
\varphi=31^{\circ} 32^{\prime} 35,79^{\prime \prime}\end{array}$ \\
\hline 5 & Kepadatan Relatif (Dr) & 0,593 \\
\hline 6 & $\begin{array}{l}\text { Modulus Elastisitas (EI) } \\
\text { - Diameter 1 } \\
\text { - Diameter 1,25 } \\
- \text { Diameter 1,5 }\end{array}$ & $19369297 \mathrm{~kg} / \mathrm{cm}^{2}$ \\
$29370472 \mathrm{~kg} / \mathrm{cm}^{2}$ \\
\end{tabular}

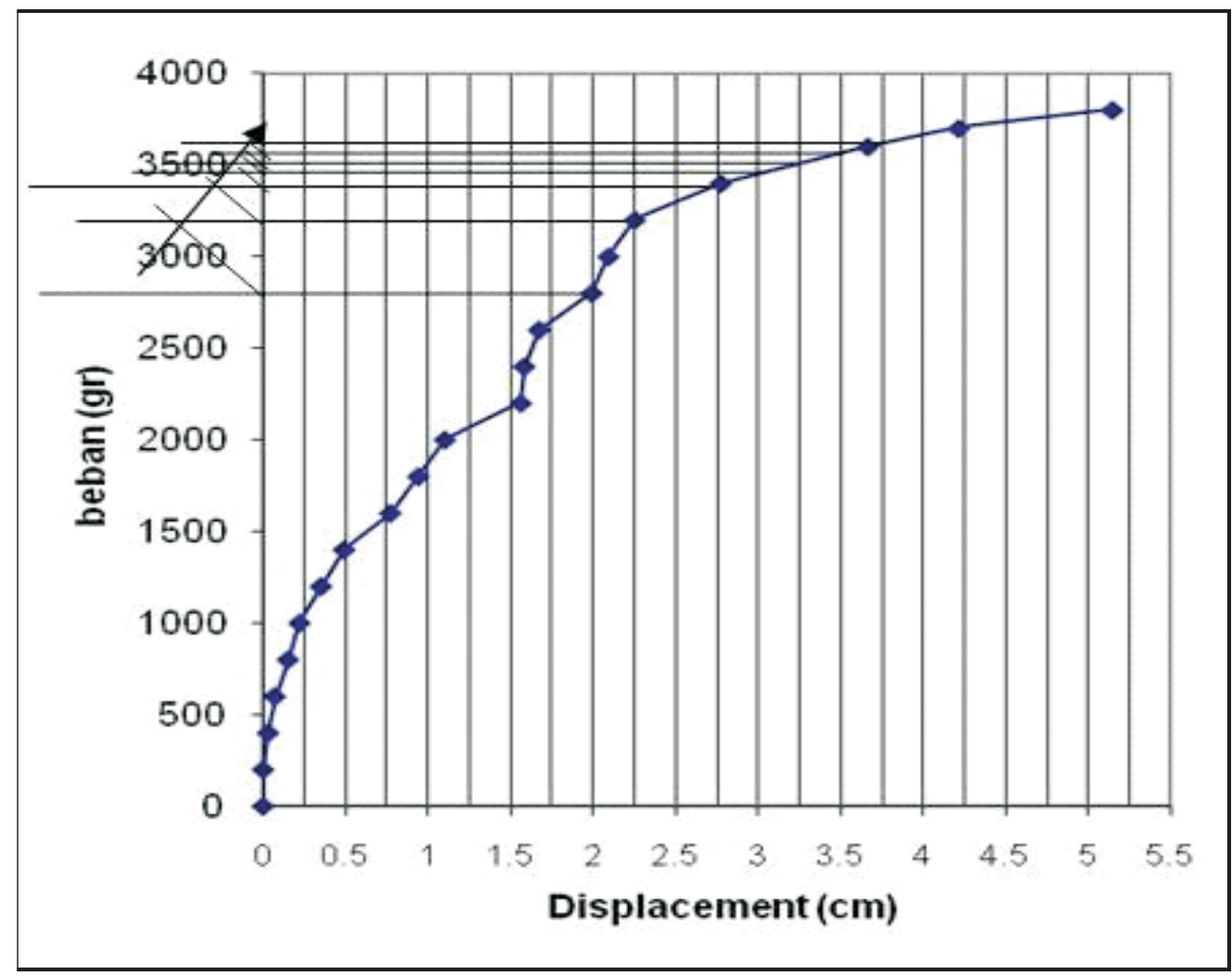

Gambar 3 : Metode Mazurkiewicz's pada tiang ujung tertutup diameter $1,5 \mathrm{~cm}$

Tabel 2. Persentase Selisih Qu Metode Mazurkiewicz's ujung terbuka dengan ujung tertutup

\begin{tabular}{|c|c|c|c|}
\hline $\begin{array}{c}\text { Diameter } \\
(\mathrm{cm})\end{array}$ & $\begin{array}{c}\text { Qu dengan } \\
\text { Mazurkiewicz's } \\
\text { Ujung Terbuka } \\
(\mathrm{gr})\end{array}$ & $\begin{array}{c}\text { Qu dengan } \\
\text { Mazurkiewicz's } \\
\text { Ujung Tertutup } \\
(\mathrm{gr})\end{array}$ & $\begin{array}{c}\text { Persentase Selisih } \\
\text { metode Mazurkiewicz's } \\
\text { Ujung Terbuka dengan } \\
\text { Ujung Tertutup } \\
(\%)\end{array}$ \\
\hline 1 & 2320 & 3326 & $-30,25$ \\
\hline 1,25 & 4550 & 3395 & 34,02 \\
\hline 1,5 & 4700 & 3750 & 34,29 \\
\hline \multicolumn{3}{|c|}{ Rata-rata } \\
\hline
\end{tabular}


Tabel 3. Persentase Selisih Qu Analisis Metode Brom dengan Interpretasi Data Metode Mazurkiewicz's

\begin{tabular}{|c|c|c|c|c|c|}
\hline $\begin{array}{l}\text { Diameter } \\
\quad(\mathrm{cm})\end{array}$ & $\begin{array}{l}\text { Qu dengan } \\
\text { Broms } \\
\text { Ujung } \\
\text { Tertutup } \\
\text { dan } \\
\text { Terbuka } \\
\text { (gr) }\end{array}$ & $\begin{array}{c}\text { Qu dengan } \\
\text { Mazurkiewicżs } \\
\text { Ujung Terbuka } \\
\text { (gr) }\end{array}$ & $\begin{array}{c}\text { Persentase } \\
\text { Selisih } \\
\text { Mazurkiewicz's } \\
\text { Ujung Terbuka } \\
\text { dengan Brom } \\
(\%)\end{array}$ & $\begin{array}{c}\text { Qu dengan } \\
\text { Mazurkiewicz's } \\
\text { Ujung Tertutup } \\
\text { (gr) }\end{array}$ & $\begin{array}{l}\text { Persentase } \\
\text { Selisih } \\
\text { Mazurkiewicz's } \\
\text { Ujung Tertutup } \\
\text { Brom } \\
(\%)\end{array}$ \\
\hline 1 & 3267,81 & 2320 & $-28,99$ & 3326 & 1.8 \\
\hline 1,25 & 4087,76 & 4550 & 11.31 & 3395 & -16.95 \\
\hline 1,5 & 4901,71 & 4700 & -4.12 & 3750 & -28.6 \\
\hline \multicolumn{3}{|c|}{ Rata-rata } & -7.27 & Rata-rata & -14.58 \\
\hline
\end{tabular}

Hasil perhitungan dengan metode Brom untuk ujung bawah tertutup dan terbuka dapat dilihat di Tabel 3. Dari tabel 3 dapat dilihat bahwa hasil interpretasi data cenderung lebih kecil dibandingkan hasil analisa. Pada tiang ujung terbuka mempunyai selisih lebih kecil sebesar 7,27 $\%$, sedangkan pada tiang ujung tertutup mempunyai selisih lebih kecil sebesar 14,58 $\%$ dibandingkan hasil analisa. Hasil interpretasi data tiang ujung terbuka cenderung lebih mendekati hasil analisa metode Brom dibandingkan tiang ujung tertutup. Perbedaan ini disebabkan karena metode Brom tidak memisahkan perhitungan tahanan lateral antara ujung bawah terbuka dengan ujung bawah tertutup.

\section{KESIMPULAN}

Berdasarkan hasil dan pembahasan diatas dapat diperoleh kesimpulan bahwa tahanan lateral $(\mathrm{Qu})$ ujung terbuka cenderung lebih besar $12,69 \%$ daripada ujung tertutup. Persentase selisih yang berbeda-beda dari masing-masing diameter disebabkan oleh pengaruh pemancangan yang menyebabkan tahanan lateral ultimit tiang naik dan pengaruh penutupan ujung bawah tiang yang mengurangi tahanan dari dalam tiang sehingga tahanan lateral ultimitnya berkurang. Pada tiang ujung terbuka mempunyai selisih lebih kecil sebesar 7,27 \% dibandingkan hasil analisa, sedangkan pada tiang ujung tertutup mempunyai selisih lebih kecil sebesar 14,58 $\%$ dibandingkan hasil analisa. Hasil interpretasi data tiang ujung terbuka cenderung lebih mendekati hasil analisa metode Brom dibandingkan tiang ujung tertutup. Perbedaan ini disebabkan karena metode Brom tidak memisahkan perhitungan tahanan lateral antara ujung bawah terbuka dengan ujung bawah tertutup.

Analisis data pengujian perlu dikaji lebih lanjut seperti dengan variasi tiang pancang kelompok, dengan memodelkan tiang miring (batter piles), dengan menerapkan jenis pembebanan dinamis dan siklis untuk mengetahui pengaruhnya terhadap perilaku tiang.

\section{DAFTAR PUSTAKA}

1. Bowles, J.E. 1991. Analisa dan Disain Pondasi Jilid 2. Jakarta: Erlangga.

2. Hardiyatmo, H.C. 2001. Teknik Fondasi II. Yogyakarta: Universitas Gadjah Mada.

3. Poulos, H.G. and Davis, E.H.1980. Pile Foundation Analysis and Design. New York: John Wiley \&Sons.

4. Wesley, L.D. 1977. Mekanika Tanah (Cetakan ketujuh). Jakarta: Badan Penerbit Pekerjaan Umum.

5. Suryolelono, K.B. 1994. Teknik pondasi Bagian II. Yogyakarta: Nafiri.

6. Prakash, Shamser, and Hari, D. Sharma. 1990. Pile Foundation in Engineering Practise. John Wiley \& Sons.

Pradoto, S. 1988. Teknik Pondasi. Bandung: Laboratorium Geoteknik Pusat Antar Universitas IImu Rekayasa ITB. 
Perbandingan Kapasitas Lateral Tiang Pancang Tunggal (Short Pile) Kondisi Fixed End Antara Ujung Bawah Terbuka Dengan Tertutup Pada Tanah Pasir (Non-Kohesif) (Indra Setya Putra)

8. Kumoro. 2004. Studi Kapasitas Lateral Model Pondasi Tiang Ujung Jepit dengan Variasi Diameter dan Kedalaman Model Pada tanah Granuler. Skripsi, Jurusan Teknik Sipil Fakultas Teknik. Surakarta: Universitas Sebelas Maret.

\section{RIWAYAT PENULIS}

Indra Setya Putra, lahir di Kudus pada 09 Desember 1981. Menamatkan pendidikan di Universitas Sebelas Maret dalam bidang Teknik Sipil Konstruksi. Saat ini bekerja sebagai peneliti muda di Puslitbang Sumber Daya Air, Kementerian PU, Bandung. 